\section{Cardiac Papillary Fibroelastoma as a Cause of Recurrent Stroke}

Živojin S. Jonjev, Milenko I. Rosić, Vladimir Torbica, Slavica Majdevac, Nataša Gocić

\author{
University in Novi Sad, Institute for \\ Cardiovascular Diseases of Vojvodina \\ Clinic of Cardiovascular Surgery, \\ Novi Sad, Serbia

Correspondence
Živojin S. Jonjev, MD, PhD
Institute for Cardiovascular Disease
of Vojvodina
Clinic of Cardiovascular Surgery
Institutski put 4
21204 Sremska Kamenica, Serbia
Phone: + 381642182367
Fax: + 381216622059
E-mail: jonjevz@nscable.net

Papillary fibroelastoma (PF) is a rare cardiac tumor usually complicated by unclear embolic events ${ }^{1}$. Most of the cases are diagnosed postmortem, at autopsy. However, improved imaging modalities and routine echocardiography examinations demonstrated that the true incidence of this phenomenon is underestimated ${ }^{2}$. PF in left atrium is not commonly seen in cardiac surgery departments so we report a case of a young woman, free of traditional cardiac risk factors, who required emergency surgery due to a left atrial mass complicated by recurrent cerebral vascular events.

Case Presentation. A 64-years-old woman was transferred from an outside hospital with a documented left atrial mass. Prior to admission the patient had transient cerebral ischemic event with loss of consciousness, collapse and consecutive left radial bone fracture. Medical history was positive for a previous stroke which had occurred two months previously, with left hemiparesis and complete recovery. Chest roentgenogram demonstrated borderline size heart, and electrocardiogram confirmed normal sinus rhythm $(\mathrm{HR}=67 / \mathrm{min})$. Transthoracic echocardiogram revealed normal left ventricular systolic function $(\mathrm{EF}=64 \%)$, and presence of an echogenic left atrial mass. Transesophageal echocardiography (TEE) confirmed a mobile mass $(2.3 \mathrm{~cm} \times 1.8 \mathrm{~cm})$ attached to the lateral wall of the left atrium, just below the left appendage, without mitral valve obstruction (Figure 1). Coronary angiography showed no atherosclerotic changes, and patient was selected for emergency heart surgery to reduce the risk of early recurrence of embolic events.

The heart was arrested and standard on-pump procedure was carried out. A yellow-white tumor with incorporated minor thrombus on the tumor surface was identified by mini transseptal approach. Smooth, gelatinous tissue was resected (Figure 2), and the mitral apparatus and left atrium were left intact. Histological examination of the specimen confirmed cardiac PF (Figure 3). The postoperative course of the patient was uneventful, and she was discharged 7 days after surgery.

Discussion. Cardiac PF is a rare primary benign tumor, produced from the endocardial components (elastic, and fibrous tissue) assembled in a gelatinous mass, and at-

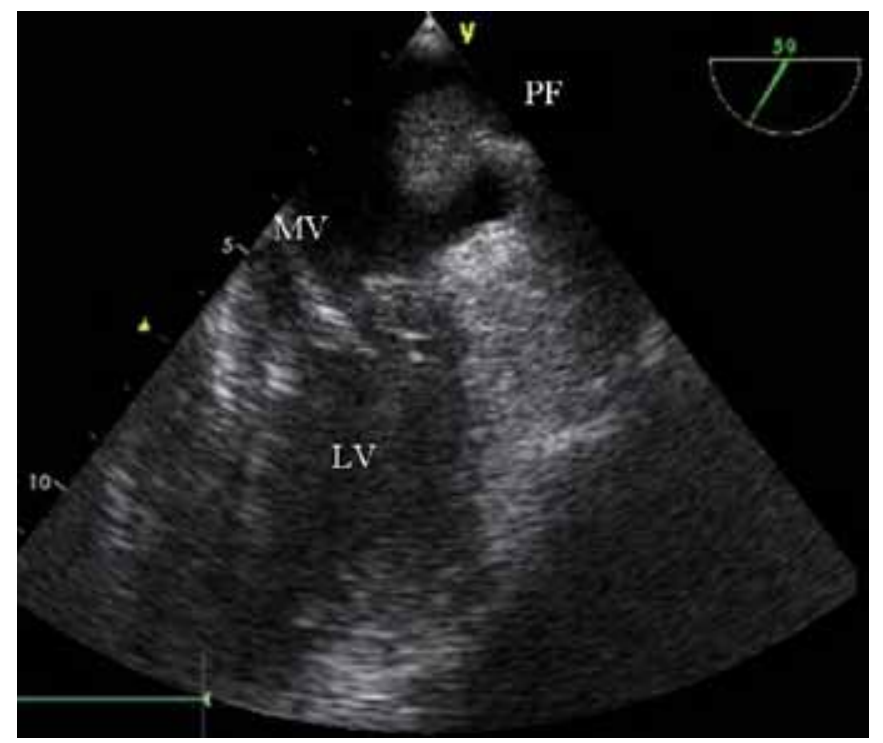

Figure 1. Intraoperative transesophageal echocardiography before cardiac arrest shows tumor attached to the lateral wall of the left atrium, just below the left appendage. $\mathrm{PF}=$ papillary fibroelastoma; $\mathrm{MV}=$ mitral valve; $\mathrm{LV}=$ left ventricle. 


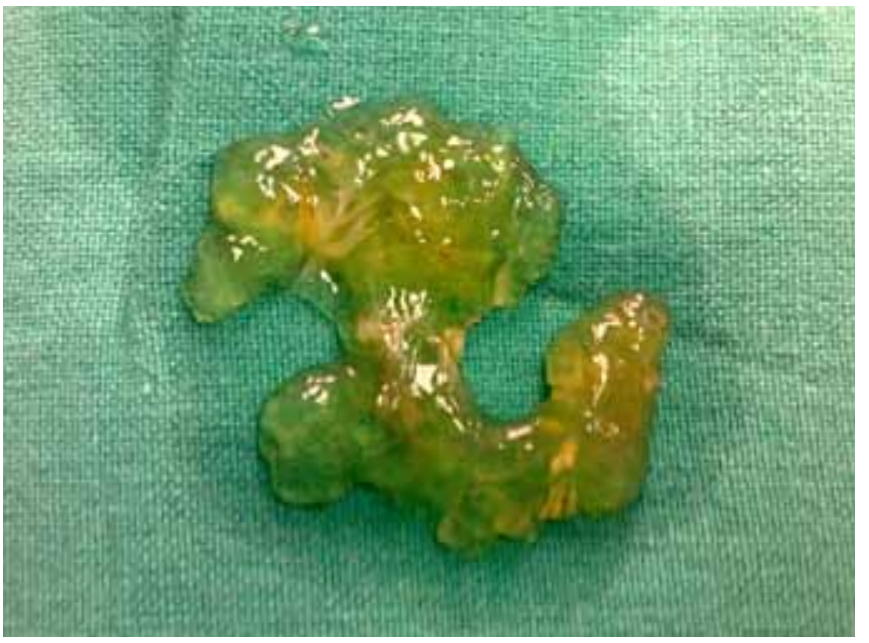

Figure 2. Gross view of the gelatinous excised mass with minor thrombus incorporated on the tumor surface.

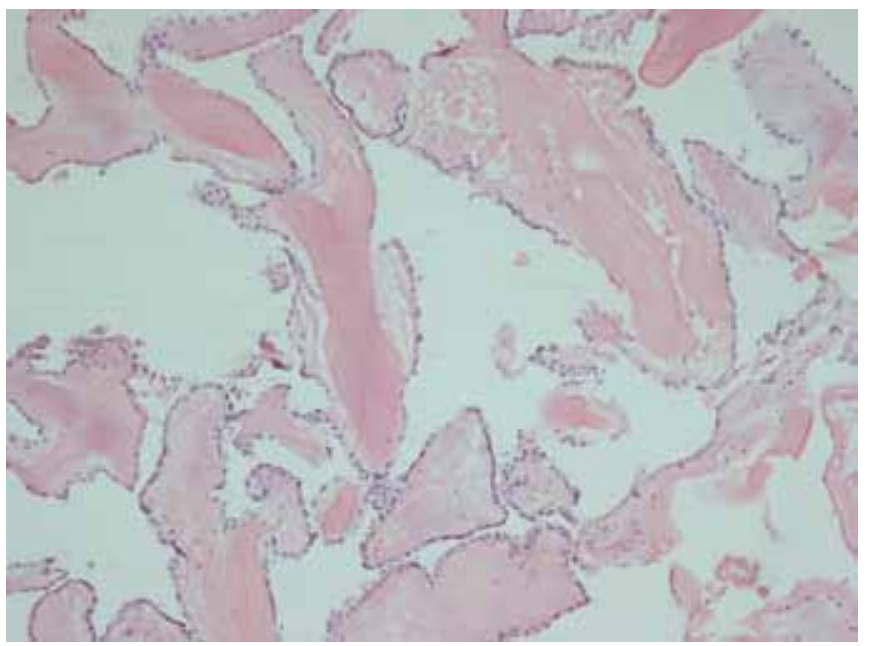

Figure 3. Histological section of the resected papillary fibroelastoma. Tumor presents with avascular papillary fronds covered with single layer endothelial cells. (Haematoxyllin and eosin stain, original magnification $x$ 25.)

tached to the endocardium by a pedicle ${ }^{1}$. Theoretically, $\mathrm{PF}$ could arise from any endocardial surface; however, it is frequently seen on the cardiac valves. PF in the left atrium is atypical and during the last two decades only 6 cases with such localization have been reported in the literature. PF exhibit no gender association, and presents most commonly between the third and fifth decades of life $[1 ; 2]$. Historically, cardiac PF was an incidental autopsy finding $(<1 \%)$, with undetermined clinical significance. At the present time, thanks to modern echocardiography, such tumors are relatively easy to detect and its incidence and clinical importance seems to be underestimated. PF in the adult is usually misdiagnosed with valve vegetations or tumor mass due to similar echocardiographic visualization ${ }^{2-3}$. Thus, TEE has been established to be the optimal imaging technique for PF diagnosis, while cardiac catheterization is considered only to investigate associated cardiac malformations.

Symptomatic cases with embolic complications, such as stroke, suggest that cardiac PF should be considered as a potentially dangerous disease with preventable complications $^{3-4}$. Surgical excision should be performed as early as possible to reduce the risk of early recurrences of embolic events. In our case, mini transseptal approach to left atrium was used ${ }^{5}$. This maneuver helped us to make a clear, sharp excision but to keep mitral valve and left atrium intact. A thrombus found on the tumor surface is an important clinical finding and supports the theory that recurrent strokes could be seen not only due to PF embolization but secondary to damage along the endothelial surface and subsequent thrombosis ${ }^{1-6}$.

In conclusion, we report a very rare case of atrial PF as a cause of recurrent cerebral event in an adult. Urgent surgical excision of PF tissue had a favorable outcome. The patient survived the operation without postoperative complications and was well and without recurrence six month after surgery.

\section{References}

1. Kuwashiro T, Toyoda K, Otsubo R, Ishibashi-Ueda H, Tagusari $\mathrm{O}$, and Minematsu K. Cardiac papillary fibroelastoma as a couse of embolic stroke: ultrasound and a hystopathological characteristics. Inter Med 2009;48:77-80.

2. Tsukube T, Ataka K, Taniguchi T, Yokoyama M, and Hanioka K. Papillary fibroelastoma of the left atrial appendage: echocardiographic findings. Ann Thorac Surg 2000;70:1416-17.

3. Howard R. A, Aldea G. S, Shapira O. M, Kasznica J. M, and Davidoff R. Papillary fibroelastoma: increasing recognition of a surgical disease. Ann Thorac Surg 1999;68:1881-5.

4. Evans A. N, Massad M. G, Gandhi S, and Ferrer K. Cardiac papillary fibroelastoma. European Journal of Cardio-Thoracic Surgery 2002;21:1120.

5. Jonjev Z. S, Mijatov M, Fabri M, Popovic S, and Radovanovic N. D. Systematic reductive annuloplasty of the mitral and tricuspid valves in patients with end-stage ischemic dilated cardiomyopathy. J Card Surg 2007;22:111-6.

6. Grinda J. M, Couetil J. P, Chauvaud S, D’Attellis N, Berrebi A, Fabiani J. N, Deloche A, and Carpentier A. Cariac valve papillary fibroelastoma: Surgical excission for revealed or potential embolizaton. J Thorac Cardiovasc Surg 1999;117:106-10. 